\title{
HILL REACTION RATES OF CHLOROPLASTS FROM VIRUS-INFECTED TOBACCO (Nicotiana tabacum L.)
}

By

MILTON C. ARCHER, JR.

\begin{abstract}
A DISSERTATION PRESENTED TO THE GRADUATE COUNCIL OF THE UNIVERSITY OF FLORIDA

IN PARTIAL FULFILLMENT OF THE REQUIREMENTS FOR THE. DEGREE OF DOCTOR OF PHILOSOPHY
\end{abstract}

UNIVERSITY OF FLORIDA

1969 


\section{ACKNOWLEDGMENTS}

I am indebted to many people for their help and consideration in my research and in the writing of this dissertation.

First, thanks are due Dr. L. H. Purdy for the financial assistance that made graduate study possible.

I am grateful to Drs. D. E. Purcifull, F. W. Zettler, J. R. Edwardson, H. E. Warmke, and E. Hiebert for their help and use of their facilities. I would also like to thank Richard Christie, Steve Christie, and Norma Cordon for their fine technical assistance.

My special thanks go to Drs. T. E. Humphreys, D. S. Anthony, and $J$. W. Kimbrough for their critical interest in my academic preparation and research efforts.

Dr. D. A. Roberts has been most understanding and encouraging throughout my residence in graduate school. He has spent countless hours discussing problems, indicating possible solutions, and sharing my excitement over results. Ever enthusiastic, he guided my program with concern, but with the wisdom and restraint that allowed me to develop as an individual. 
TABLE OF CONTENTS

ACKNOWLEDGMENTS . . . . . . . . . . . . . . . . . i1 LIST OF TABLES . . . . . . . . . . . . . . . . iv LIST OF FIGURES . . . . . . . . . . . . . . . . . V INTRODUCTION . . . . . . . . . . . . . . . . . 1 MATERIALS AND METHODS . . . . . . . . . . . . . 6 RESULTS . . . . . . . . . . . . . . . . . 10 DISCUSSION . . . . . . . . . . . . . . . . 22 SUMMARY . . . . . . . . . . . . . . . . 32 LITERATURE CITED . . . . . . . . . . . . . . 34 BIOGRAPHICAL SKETCH . . . . . . . . . . . . 38 


\section{LIST OF TABLES}

Table

Page

1. Hill reaction rates of spinach chloroplasts isolated in various buffers . . . . . 15

2. Hill reaction rates of tobacco chloroplasts isolated in Tris-HCl and Tricine$\mathrm{NaOH}$. . . . . . . . . . . . . 17

3. Hill reaction rates of spinach and tobacco chloroplasts isolated in Tricine-NaOH . . . . . . . . . . . . . 19

4. Hill reaction rates of chloroplasts from healthy and virus-infected tobacco... . . . . . . . . . . 20 


\section{LIST OF FIGURES}

Figure

Page

1. Rates of $\mathrm{FeCN}^{-3}$ reduction as a function of chlorophyll concentration. Chloroplasts were isolated in Tricine-NaOH and assayed in Tris-HCl . . . . . . . . . 11

2. Absorption spectra of chlorophyll and ferricyanide, separately and mixed. Curve a is $1.5 \mu$ moles $\mathrm{FeCN}^{-3}$; curve $\mathrm{b}$ is $20 \mu \mathrm{g}$ chlorophyll from tobacco tissue isolated in Tricine-NaOH; curve $\mathrm{c}$ is 1.5 pmoles $\mathrm{FeCN}^{-3}$ plus $20 \mu \mathrm{g}$ chlorophyll; curve $\mathrm{d}$ is the sum of curves $\mathrm{a}$ and $\mathrm{b} ; \mathrm{H}_{2} \mathrm{O}$ added to $\mathrm{a}$ total volume of $3 \mathrm{ml}$ in each cuvette . . . . 13

3. Time course of $\mathrm{FeCN}^{-3}$ reduction by tobacco chloroplasts isolated in Tricine- $\mathrm{NaOH}$ and assayed in Tris-HCl . . . . . . . . . 14

4. Electron transport path of photoreactions in isolated chloroplasts (6) . . . . . . 29 


\section{INTRODUCTION}

Büchner's (9) discovery in 1897 that yeast enzymes can carry out extra-cellular fermentation stimulated systematic attempts to reproduce total photosynthesis outside the living cell. This goal was not reached, however, until 1954, when Arnon et al. (3) demonstrated in a cell-free system the assimilation of $\mathrm{CO}_{2}$ and its reduction to the level of carbohydrate.

Hill (18), by 1939, had found that isolated chloroplasts, when illuminated, could evolve oxygen when $\mathrm{CO}_{2}$ was replaced by ferric oxylate. Since then, other non-physiological electron acceptors, such as benzoquinone and ferricyanide $\left(\mathrm{FeCN}^{-3}\right)$, have been used to replace $\mathrm{CO}_{2}$ (32). Also, Arnon et al. (4) have recently presented evidence that the iron-bearing protein ferredoxin, present in all photosynthetic cells, plays a key role in the electron transport pathway to the reduction of $\mathrm{CO}_{2}$.

$\mathrm{FeCN}^{-3}$ has been the oxidant used most widely in studies of the Hill reaction. It is relatively specific, has a high oxidation-reduction potential, and is non-autoxidizable (7). Most workers $(5,16,33)$ have measured Hill reaction 
activity by following the decrease in optical density (OD) of $\mathrm{FeCN}^{-3}$ at $420 \mathrm{~m} \mu$.

of the chemical reactions involved in photosynthesiś, the Hill reaction is least demanding in its requirements for isolation of chloroplasts. The reaction can be carried out with preparations of chloroplasts that will not support photophosphorylation or $\mathrm{CO}_{2}$ fixation. Isotonic sugar solutions were first used (18) to isolate chloroplasts and later, in attempts to demonstrate $\mathrm{CO}_{2}$ fixation, isotonic solutions of $\mathrm{NaCl}$ were used (3). Either seemed satisfactory for sustaining Hill reaction rates (4). Present evidence indicates, however, that sugar solutions are superior to salt solutions for both the Hill reaction and $\mathrm{CO}_{2}$ fixation (22) .

Two recent innovations have increased experimentally obtained photosynthetic rates, whether measured by the Hill reaction or by $\mathrm{CO}_{2}$ fixation. First, Good et al. (16), who studied the synthesis, properties, and usefulness of buffers for the reaction mixtures, found that Tricine-NaOH was the most effective of 12 buffers tested. Jensen and Bassham (21), using two of these buffers, also prepared chloroplasts that supported very high rates of $\mathrm{CO}_{2}$ fixation. Cockburn et al. (12), who isolated chloroplasts in pyrophosphate-HCl and resuspended them in another of the buffers described by 
Good et al. (16), reported $\mathrm{CO}_{2}$ fixation rates comparable to those obtained by Jensen and Bassham (21).

The second innovation for increasing photosynthetic rates $(11,30,31)$ consisted of drastically reducing the time of grinding leaf tissue and for completing other steps in the isolation procedure. The importance of maintaining temperatures close to $0^{\circ} \mathrm{C}$ for all operations has been stressed by most workers.

The plant tissues used most widely for chloroplast isolation have been those of spinach (Spinacia oleracea L.), pea (Pisum sativum L.), and Swiss chard (Beta vulgaris L.). Many of the questions concerning the complex mechanisms of photosynthesis have been answered by experiments in which these plants were used. In the field of plant virology, however, these plants are of limited value because they are susceptible to relatively few viruses. Tobacco (Nicotiana tabacum L. 'Samsun $N^{\prime}$ '), which is susceptible to many viruses, is easily grown and is a useful test and assay plant.

One purpose of this paper is to compare the Hill reaction rates of spinach and tobacco, to determine if tobacco can serve as well as spinach in determining photosynthetic rates. Also, it was thought desirable to test several buffer systems for isolation of chloroplasts in 
order to find the one that would support the highest Hill reaction rates. Having found the optimum buffer system, the effects of several viruses on photosynthetic activities in tobacco could be investigated.

Photosynthetic activity in plants associated with virus activity is usually adversely affected, most obviously in those that are wholly or partly necrotic. Also, chlorotic tissue contains less chlorophyll and has lower rates of photosynthesis than healthy tissue $(13,17,26)$. Reduction in photosynthesis is not just a matter of chlorophyll destruction, however. Roberts and Corbett (27) found lower rates of $\mathrm{O}_{2}$ evolution/mg chlorophyll in leaf discs of tobacco ringspot virus (TRSV)-infected plants than in healthy tissue. Spikes and stout (29) reported reduced Hill reaction activity in chloroplasts from sugar beets infected with beet yellows virus. Zaitlin and Jagendorf (33) found that chloroplasts from virus-infected tobacco grown under conditions of nitrogen stress supported lower rates of the Hill reaction and of photophosphorylation than those from comparable healthy plants.

Viral infections do not always decrease photosynthetic rates, however. Hopkins and Hampton (20) detected no difference in the light reactions of photosynthesis between healthy and tobacco etch virus (TEV)-infected plants. 
Archer (1), in a preliminary report, found increased Hil1 reaction rates in chloroplasts from recovered tissue of TRSV-infected.plants. Goffeau and Bové (14) reported increased Hill reaction activity and higher rates of photophosphorylation in hypersensitive leaves of Chinese cabbage infected with turnip yellow mosaic virus; the increase was correlated with the phase of most active virus multiplication.

It is obvious that photosynthetic activity may vary with the stage and type of virus infection. The other purpose of this paper is to investigate Hill reaction activity of three plant-virus combinations: Symptomless tobacco leaves chronically infected with TRSV; chlorotic tobacco leaves systemically infected with TEV; uninfected tissue of tobacco plants inoculated with tobacco necrosis virus (TNV). 
MATERTALS AND METHODS

Spinacia oleracea L. 'Bloomsdale' was purchased at a local supermarket and tobacco leaves were from greenhousegrown plants of Nicotiana tabacum L. 'Samsun NN.' Young, fully expanded spinach leaves and tobacco leaves $6-12 \mathrm{~cm}$ wide were used in experiments comparing various buffer systems for isolation of chloroplasts.

Young (3-4 leaves) tobacco plants were mechanically inoculated with TEV 21 days prior to isolation of chloroplasts from the top 3-4 leaves, each of which was at least $8 \mathrm{~cm}$ long. Symptoms at the time of harvest included stunting and mild mottling. Control leaves were from plants originally rubbed with juice from healthy tobacco plants. Young tobacco plants were also mechanically inoculated with TRSV and assayed 20 and 30 days after inoculation; recovered leaves and healthy leaves of comparable size were used for assay. Control leaves were from comparable plants initially rubbed with juice from healthy tobacco plants.

Plants used for experiments with TNV were topped and trimmed to two opposite leaves with widths of at least $8 \mathrm{~cm}$. One lateral half of each leaf was mechanically inoculated 
with the virus or rubbed with juice from healthy tobacco plants; the opposite half-leaf was used for isolation of chloroplasts 3 days after inoculation.

All plants were darkened $24 \mathrm{hr}$ prior to preparation of chloroplasts to permit starch catabolism (24).

Chloroplasts were obtained from $20 \mathrm{~g}$ of pre-chilled laminar tissue homogenized $5 \mathrm{sec}$ in a Waring Blendor at high speed in $80 \mathrm{ml}$ of partially frozen buffer; the homogenate was squeezed through 4 layers of cheesecloth, poured into 2 tubes, and subjected to various centrifugal speeds and cycles; each final pellet was gently resuspended in 1 ml of buffer with a cotton-tipped glass stirring rod; the chloroplast suspensions were put on ice and kept in the dark until ready for use. All operations were carried out at $4^{\circ} \mathrm{C}$.

There were four variations of this general isolation procedure. 1) Tissue was homogenized in a buffer containing $0.05 \mathrm{M}$ tris (hydroxymethyl)-aminomethane (Tris), $0.33 \mathrm{M}$ sucrose, $0.01 \mathrm{M} \mathrm{NaCl}, 0.01 \mathrm{M}$ EDTA, and $\mathrm{HCl}$ to $\mathrm{pH} 7.8$. The homogenate was centrifuged $90 \mathrm{sec}$ at $500 \mathrm{~g}$ and the resulting supernatant fraction $7 \mathrm{~min}$ at $1000 \mathrm{~g}$. Each final pellet was resuspended in $1 \mathrm{ml}$ of the original buffer. 2) Tissue was treated as described above, but N-tris (hydroxymethyl)methyl glycine (Tricine) was substituted for Tris and $\mathrm{pH}$ 
7.8 was obtained by adding NaOH. 3) Tissue was homogenized in a buffer containing $0.05 \mathrm{M} 2$ (N-morpholino) ethanesulfonic acid (MES), $0.33 \mathrm{M}$ sucrose, $0.002 \mathrm{M} \mathrm{NaNO}_{3}, 0.002 \mathrm{M}$ EDTA, $0.001 \mathrm{M} \mathrm{MnCl}_{2}, 0.001 \mathrm{M} \mathrm{MgCl}_{2}, 0.0005 \mathrm{M} \mathrm{K}_{2} \mathrm{HPO}_{4}, 0.02 \mathrm{M} \mathrm{NaCl}$, and $\mathrm{NaOH}$ to $\mathrm{pH} 6.1$. The homogenate was centrifuged $50 \mathrm{sec}$ at $2000 \mathrm{~g}$, and the pellets were resuspended in a buffer identical to the first, except that MES was replaced with $\mathrm{N}-2$ hydroxyethylpiperazine-N'-2-ethanesulfonic acid (HEPES) and $\mathrm{NaOH}$ to $\mathrm{pH} 7.8$. 4) Tissue was homogenized in a buffer containing $0.01 \mathrm{M}$ pyrophosphate, $0.33 \mathrm{M}$ sucrose, $0.005 \mathrm{M} \mathrm{MgCl}_{2}$, and $\mathrm{HCl}$ to $\mathrm{pH}$ 6.5. This buffer was prepared each time just prior to use. The homogenate was centrifuged at $4000 \mathrm{q}$ for $90 \mathrm{sec}$ (rest to rest), and the pellets were resuspended in a buffer containing $0.05 \mathrm{M}$ HEPES, $0.33 \mathrm{M}$ sucrose, $0.001 \mathrm{M}$ $\mathrm{MgCl}_{2}, 0.001 \mathrm{M} \mathrm{MnCl}_{2}, 0.002 \mathrm{M} \mathrm{EDTA}$, and $\mathrm{NaOH}$ to $\mathrm{pH} 7.8$. Method 1) is essentially the one used by Avron et al. (5) and method 2) is an innovation of Good et al. $(15,16)$, in which Tricine is used instead of Tris. Method 3), proposed by Jensen and Bassham (21), provides for high rates of $\mathrm{CO}_{2}$ assimilation. Method 4) is a chemically inexpensive procedure in which rates of $\mathrm{CO}_{2}$ uptake are slightly greater than those obtained by the third method (12).

Chlorophyll concentrations were determined by Arnon's method (2); the chloroplasts were then diluted to $200 \mu \mathrm{g}$ 
chlorophy $11 / \mathrm{ml}$ for methods 1) and 2) and to $100 \mu \mathrm{g} / \mathrm{ml}$ for methods 3) and 4).

Hill reaction rates, in which $\mathrm{FeCN}^{-3}$ was the oxidant, were measured spectrophotometrically. Change ln OD was measured at $420 \mathrm{~m} \mu$. Cuvettes contained $40 \mu$ moles of either Tris-HCl or Tricine-NaOH at pH 7.8, 88 umólể Nầc1, 1.5 umoles $\mathrm{FeCN}^{-3}, 0.1 \mathrm{ml}$ of chloroplast suspension containing either 10 or $20 \mu \mathrm{g}$ chlorophyll, and $\mathrm{H}_{2} \mathrm{O}$ to a total of $3 \mathrm{mil}$. Illumination was at 44,000 lux for $2 \mathrm{~min}$, using cuvettes minus the $\mathrm{FeCN}^{-3}$ as blanks. All rate determinations were made at approximately $21^{\circ} \mathrm{C}$ and within $3 \mathrm{hr}$ of isolation of the chloroplasts. 


\section{RESULTS}

There was a large daily variability in the Hill reaction rates from similarly grown plants. This was moderated by using a standard pre-darkening period (23) and by carefully replicating the isolation procedures.

Although no detailed data were taken, the tobacco tissue consistently fit the pattern reported by zaitlin and Jagendorf (33), inasmuch as chloroplasts from young leaves reduced $\mathrm{FeCN}^{-3}$ at lower rates than those from older and fully expanded leaves.

Spinach or tobacco chloroplasts isolated in Tricine$\mathrm{NaOH}$ and assayed in Tris-HCl at a chlorophyll concentration of $30 \mu \mathrm{g} / 3 \mathrm{ml}$ had initial oD readings that varied as much as $23 \%$ in a single experiment; at $20 \mu \mathrm{g}$ chlorophyll/3 ml the variation was below $12 \%$. At the same time the rate of $\mathrm{FeCN}^{-3}$ reduction was lower at a concentration of $30 \mu \mathrm{g} / 3$ $\mathrm{ml}$ than at $20 \mu \mathrm{g} / 3 \mathrm{ml}$ when put in terms of oxidant reduced/ mg chlorophyll/hr (Fig. 1). A concentration of $30 \mu \mathrm{g}$ chlorophyll/3 ml induced a variability in $\mathrm{FeCN}^{-3}$ reduction rates of 22 and 11\%, respectively, in chloroplasts of spinach and tobacco when replicated three times; the rates at a 


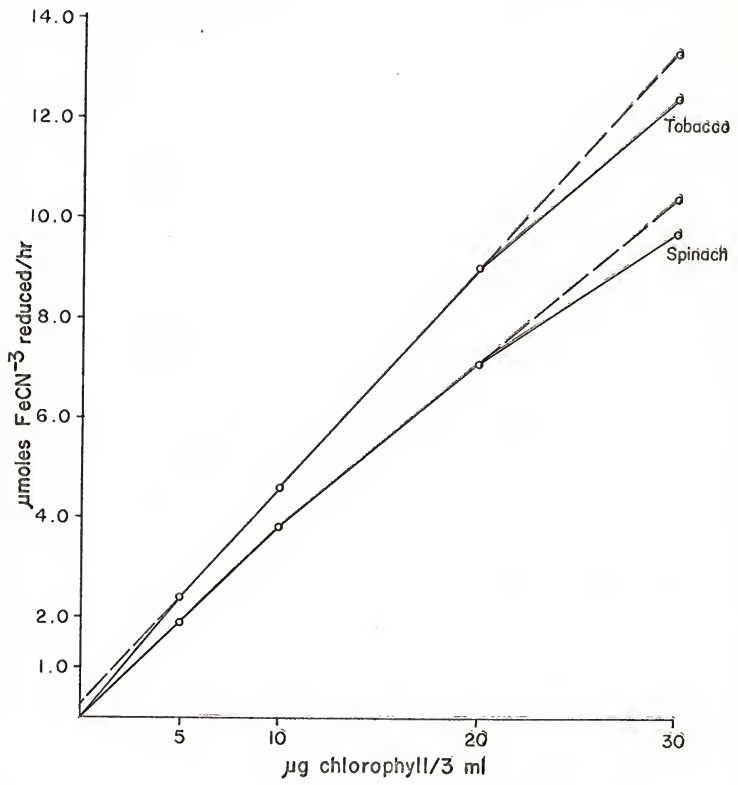

Figure 1. Rates of $\mathrm{FeCN}^{-3}$ reduction as a function of chlorophyll concentration. Chloroplasts were isolated in Tricine-NaOH and assayed in Tris-HC1. 
chlorophyll concentration of $20 \mu \mathrm{g} / 3 \mathrm{ml}$, similarly rep11cated, varied 7 and 10\%, respectively, for spinach and tobacco.

For the reasons of reproducibility of initial readings and $O D$ changes and the slightly higher specific activity/mg chlorophyll supported by $20 \mu \mathrm{g}$ chlorophyll/3 $\mathrm{ml}$, this concentration was used instead of $30 \mu \mathrm{g}$ chlorophyll/3 $\mathrm{ml}$ when chloroplasts were isolated in Tricine$\mathrm{NaOH}$ and Tris-HCl. For the same reasons, chloroplasts isolated in pyrophosphate-HCl or MES-NaOH were assayed at a concentration of $10 \mu \mathrm{g} / 3 \mathrm{ml}$ rather than at a higher concentration.

Regardless of the concentration of chlorophyll, whether at 10,20 , or $30 \mu \mathrm{g} / 3 \mathrm{~m} 1$, the absorbances of the separate reactants $\left(\mathrm{FeCN}^{-3}\right.$ and chlorophyll) were additive; therefore, a Beer's Law plot of the $\mathrm{FeCN}^{-3}$ alone can be used to calculate its reduction by the chloroplasts (Fig, 2).

Tobacco chloroplasts exhibited the same straight-line time course for $\mathrm{FeCN}^{-3}$ reduction that has been shown for chloroplasts isolated from spinach (6). An assay time of 2 min was selected because of its standard use in this kind of test system (Fig. 3).

Spinach chloroplasts isolated in Tricine-NaOH buffer were more active than those isolated in Tris-HCl (Table 1). 


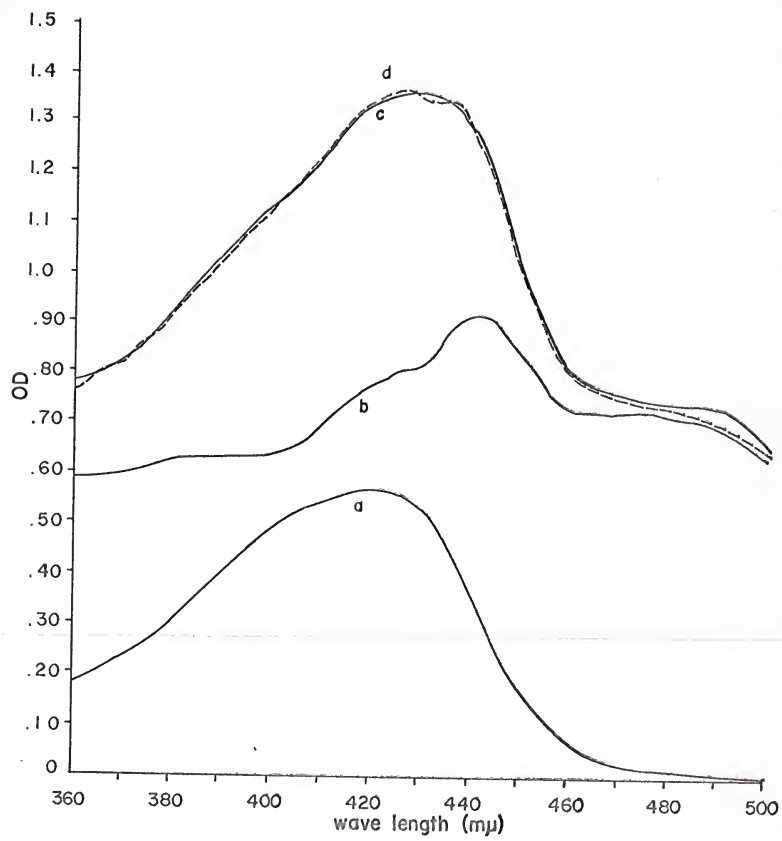

Figure 2. Absorption spectra of chlorophy11 and ferricyanide, separately and mixed. Curve a is $1.5 \mu$ moles $\mathrm{FeCN}^{-3}$; curve $\mathrm{b}$ is $20 \mu \mathrm{g}$ chlorophyll from tobacco tissue isolated in Tricine-NaOH; curve $\mathrm{C}$ is $1.5 \mu$ moles $\mathrm{FeCN}^{-3}$ plus $20 \mu \mathrm{g}$ chlorophyll; curve $d$ is the sum of curves $a$ and $b ; \mathrm{H}_{2} \mathrm{O}$ added to a total volume of $3 \mathrm{ml}$ in each cuvette. 


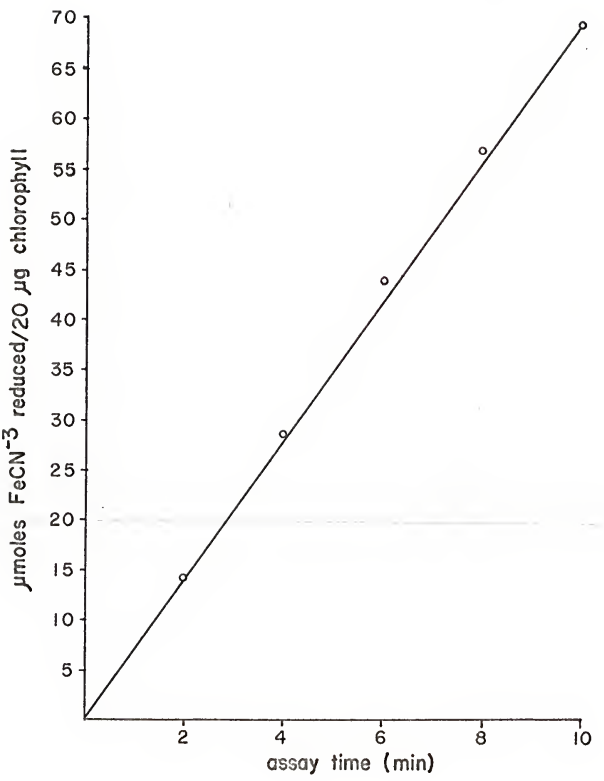

Figure 3. Time course of $\mathrm{FeCN}^{-3}$ reduction by tobacco chloroplasts isolated in Tricine-NaOH and assayed in Tris$\mathrm{HCl}$. 
TABLE 1. Hill reaction rates of spinach chloroplasts isolated in various buffers ${ }^{a}$

Reaction rates Test $^{b}$ Isolation buffer $\underset{\substack{\text { Tris-HCl } \\ \text { Assay }}}{p^{d}} \underset{\substack{\text { Tricine-NaOH } \\ \text { Äsay }}}{p^{d}}$

356

380

Tricine-NaOH

421

$<.01$

$4 \hat{2} \hat{6}$

$<.01$

2 MES-NaOH

336

321

Tricine- $\mathrm{NaOH}$

428

$<.05$

415

$<.05$

3 Pyrophosphate-HCl

21.4

1.57

Tricine-NaOH

286

$<.05$

253

$<.01$

a Rates are expressed as umoes $\mathrm{FeCN}^{-3}$ rediced/mg chlorophyll/hr.

b Test 1 consisted of three experiments with a total. of 10 replications; tests 2 and 3 consisted of two experiments with three replications each.

C The probability figure determined by the ti test for Tricine-NaOH being the better isolation buffer in each paired test. 
Rates of the Hill reaction in Tricine-NaOH-isolated chloroplasts were 18 and $12 \%$ higher, respectively, when Tricine$\mathrm{NaOH}$ and Tris-HCl were the assay buffers. Hill reaction activity of Tris-HCl-isolated chloroplasts was $7 \%$ higher in Tricine-NaOH than Tris-HCl assay buffers.

Spinach chloroplasts isolated in Tricine-NaOH reduced $\mathrm{FeCN}^{-3}$ more than $25 \%$ faster than those prepared in MES-NaOH, regardless of whether assayed in Tris-HCl or Tricine-NaOH (Table 1). Neither assay buffer was significantly better than the other in this pairing of isolation procedures. Chloroplasts of spinach isolated in Tricine-NaOH gave $34 \%$ higher Hill reaction rates than those isolated in pyrophosphate-HCl when both preparations were assayed in Tris$\mathrm{HCl}$; when assayed in Tricine- $\mathrm{NaOH}$, those isolated in Tricine$\mathrm{NaOH}$ had $61 \%$ higher rates (Table 1 ). When isolated in pyrophosphate-HCl, chloroplasts reduced $\mathrm{FeCN}^{-3} 36 \%(\mathrm{p}<.05)$ faster in the Tris-HCl assay medium than in the one containing Tricine-NaOH.

When tobacco chloroplasts were assayed in Tris-HCl, isolation in Tricine- $\mathrm{NaOH}$ gave $40 \%$ greater reduction of $\mathrm{FeCN}^{-3}$ than isolation in Tris-HCl; when assayed in Tricine$\mathrm{NaOH}$, the reaction rate was $34 \%$ higher (Table 2). When Tricine-NaOH was used for isolation, Tris-HCl was slightly better $(\mathrm{p}<.05)$ for the assay than Tricine-NaOH. 
TABLE 2. Hill reaction rates of tobacco chloroplasts isolated in $\mathrm{Tris}-\mathrm{HCl}$ and Tricine- $\mathrm{NaOH}{ }^{\mathrm{a}}$, b

Reaction rates

Isolation buffer

$$
\text { Tris-HCl }
$$

Assay

Tricine-NaOH

Assay

Tris-HCl

453

446

Tricine-NaOH

$634^{C}$

$597^{C}$

a Rates are expressed as $\mu$ moles $\mathrm{FeCN}^{-3}$ reduced/mg chlorophyll/hr.

b Based on three experiments with three replications in each.

C $\mathrm{p}<.01$ for Tricine-NaOH being the better isolation buffer by the $t$ test for paired observations. 
Spinach and tobacco chloroplasts were isolated in Tricine-NaOH in two additional experiments. When assays were made in Tris-HCl, Hill reaction rates were $44 \%$ higher in tobacco than in spinach; when the assay was made in Tricine-NaOH, rates were $33 \%$ higher (Table 3). Tris-HCl supported $8 \%$ higher rates $(p<.05)$ than Tricine-NaOH for assaying tobacco chloroplasts.

The results of the last test demonstrated the adequacy of tobacco chloroplasts for sustaining high Hill reaction rates; the effects of virus infection on the rates of these chloroplasts were then investigated. From the results of experiments on methods of isolation and assay, it was concluded that subsequent studies of Hill reaction activity of virus-infected tobacco would best be conducted by isolating the chloroplasts in Tricine- $\mathrm{NaOH}$ and assaying them in Tris$\mathrm{HC} 1$.

There was no significantly detectable difference between the rates of $\mathrm{FeCN}^{-3}$ reduction by the chloroplasts from TEVinfected and healthy tobacco plants. The leaves used in these 2 experiments were fully mature and, as such, sustained fairly high rates of Hill reaction activity (Table 4). The findings with TEV-infected tobacco are in agreement with results obtained by Hopkins and Hampton (20). These authors 
TABLE 3. Hill reaction rates of spinach and tobacco chloroplasts isolated in Tricine- $\mathrm{NaOH}^{\mathrm{a}}$, b

Reaction rates

Chloroplast source

Tris-HCl

Triciné-NaOH

Assay Assay

Spinach

337

339

Tobacco

$485^{c}$

$457^{\mathrm{C}}$

a Rates are expressed as $\mu$ moles $\mathrm{FeCN}^{-3}$ reduced/mg chlorophyll/hr.

b Based on two experiments with four replications each.

C

$\mathrm{p}<.01$ for chloroplasts of tobacco supporting higher rates than those of spinach by the $t$ test for paired observations. 
TABLE 4. Hill reaction rates of chloroplasts from healthy and virus-infected tobacco ${ }^{\mathrm{a}}, \mathrm{b}$

\begin{tabular}{clc} 
Test $^{\mathrm{C}}$ & Chloroplast source & Reaction rates \\
\hline 1 & Healthy tobacco & $581^{\prime}$ \\
& TEV-infected tobacco & 575 \\
2 & Healthy tobacco & 495 \\
& TNV-infected tobacco & 480 \\
3 & Healthy tobacco & $519 \mathrm{~d}$ \\
& TRSV-infected tobacco & $583^{\circ}$
\end{tabular}

a Chloroplasts isolated in Tricine-NaOH and assayed in Tris-HCl.

b Rates are expressed as $\mu$ moles $\mathrm{FeCN}^{-3}$ reduced/mg chlorophyll/hr.

- C Tests 1 and 2 consisted of two experiments of four replications each; test 3 consisted of two experiments with a total of 10 replication.

d Significantly different $(p<.01)$ from the figure for comparable healthy controls by the $t$ test for paired observations. 
also found (19) that dark reaction rates were decreased in the virus-infected plant.

Inoculation of half-leaves of tobaceo with TNV induced no apparent change in Hili reaction ratè of the chilồ = plasts isolated from the opposite uninfedted half-leaves (Table 4). It seems, therefore, that the systemic acquired resistance (28) initiated by a local lesion-inducing viruus does not affect the light-mediated reàtions of photosyn= thesis. There was closer agreement between experiments in this test than in other tests, probably because of the topping and trimming of the plants prior to inoculation; the leaves used were nearly uniform in siże.

Plants used in the two experiments testing Hili reaction activity in leaves chronically infected with TRSV were inoculated 20 and 30 days prior to assay, The chloroplasts from recovered leaves supported rates of $\mathrm{FeCN}^{-3}$ reduction that were $12 \%$ higher than rates of chioroplasts from controi. leaves (Table 4). Time of assay after inoculation made no apparent difference. These results are in apparent contràdiction with those obtained by Roberts and Corbett (27), who found that $\mathrm{Hill}$ reaction rates, determined by $\mathrm{O}_{2}$ evolution, were reduced in TRSV-infected tissue. Pôsibib explanàtions for this contradiction are presented later. 


\section{DISCUSSION}

Probably no other electron acceptor has been used as frequently as $\mathrm{FeCN}^{-3}$ in the study of the Hill reaction. Its main drawback is its relative insensitivity, having a molar absorption coefficient of about 1000 for oD changes at $420 \mathrm{~m} \mu$. Krogmann and Jagendorf (23) have determined the production of ferrocyanide by adding ferric iron, which is reduced to ferrous iron and complexed with o-phenanthroline. This complex has a molar absorption coefficient of 10,800. Avron and Shavit (7) have improved this technique by using a diphenyl derivative of the o-phenanthroline, which has a coefficient of 20,500 .

For the study reported here, it was not necessary to use a technique with the sensitivity of the latter two methods. Therefore, Hill reaction rates were measured with $\mathrm{FeCN}^{-3}$ as the oxidant and with a concentration of chlorophyll that makes it possible to reproduce initial oD readings.

Most researchers have used a chlorophyll concentration of $30 \mu \mathrm{g} / 3 \mathrm{ml}$ with $\mathrm{FeCN}^{-3}$ to measure Hill activity, but this concentration introduces a marked variability in the initial OD readings and does not support reduction of $\mathrm{FeCN}^{-3}$ at as 
high a rate as lower concentrations when calculated on a unit of chlorophyll basis.

As shown in Figure 1, a chlorophy11 concentration of $20 \mu \mathrm{g} / 3 \mathrm{ml}$ is better for purposes of assay than $30 \mu \mathrm{g} / 3 \mathrm{~m} 1$ when chloroplasts were isolated with Tricine-NaOH; a, chlorophyll concentration of $10 \mu \mathrm{g} / 3 \mathrm{ml}$ is best for isolating chloroplasts by the procedures involving pyrophosphate-HCl and MES-NaOH. The most probable reason for the lower concentrations' supporting higher specific activity/unit chlorophyll is the reduced light interference due to particulate, non-chloroplast material, allowing for both more consistent initial oD readings and more efficient interaction of the reactants and light. The fact that the line denoting tobacco in Figure 1 does not extrapolate to zero may also be due to the presence of particulate material even at very low concentrations of chlorophyll.

The relatively lower rates of $\mathrm{FeCN}^{-3}$ reduction with the MES-NaOH and pyrophosphate-HCl isolation procedures are supported by data obtained by other workers, who used spinach

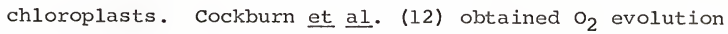
rates from 10-110 $\mu$ moles $\mathrm{O}_{2} / \mathrm{mg}$ chlorophy $11 / \mathrm{hr}$ when the pyrophosphate-HCl buffer was used. This would indicate a range of 20-220 umoles oxidant reduced/mg chlorophy11/hr. Jensen and Bassham (21), using the procedure involving MES- 
$\mathrm{NaOH}$, obtained rates of 10-90 $\mu$ moles $\mathrm{O}_{2} / \mathrm{mg}$ chlorophy $11 / \mathrm{hr}$; again, the stoichiometry of the Hill reaction would suggest a rate of 20-180 $\mu$ moles of oxidant reduced/mg chlorophyll/ hr. These rates are lower, for instance, than rates of $300 \mu$ moles obtained by Avron et al. (5) with spinach'chloroplasts isolated in Tris-HCl.

In comparing the tobacco and spinach chloroplasts isolated in Tricine-NaOH, one should note that market spinach was used; and one should probably predict that chloroplasts isolated from freshly gathered spinach leaves would support higher Hill reaction rates than are reported here. Bucke et al. (10), measuring $\mathrm{CO}_{2}$ fixation in spinach plastids, found rates in freshly harvested spinach to be 2-3 times higher than rates in market spinach.

Tricine- $\mathrm{NaOH}$ has been shown by Good (15) to be a more desirable buffer than Tris-HCl for supporting the Hill reaction in isolated chloroplasts. It has an isoelectric point of about 5.2, and raising the $\mathrm{pH}$ to the desirable buffering range with $\mathrm{NaOH}$ or $\mathrm{KOH}$ does not appreciably increase the anion concentration. The dissociation constant of Tricine (pK 7.95) is slightly better for most reaction systems than Tris (pK 8.15) (15). For these reasons, Tricine uncouples photophosphorylation less than Tris. Good 
(15) has also found that the only inhibitory action of Tricine is osmotic, similar to equimolar sucrose concentrations; but even so, it is only about half as osmotically active as Tris.

The results obtained here with spinach and tobacco isolated in Tricine-NaOH are in accord with the above findings. The fact that Tris-HCl, when used as an assay buffer for tobacco, increased the reduction of $\mathrm{FeCN}^{-3}$ may be due to a slight uncoupling of the Hill reaction from photophosphorylation.

The uncoupling phenomenon is probably also responsible for the high rates shown in Table 2 . The tobacco leaves used in these experiments were consistently larger than those used for determining the rates reported in Table 3; there is a concomitant increase in the rates of $\mathrm{FeCN}^{-3}$ reduced. Zaitlin and Jagendorf (33) have reported low ratios of photophosphorylation to Hill reaction activity in larger leaves, suggesting that phosphorylation had been uncoupled from electron transport in those leaves.

There is no doubt that viruses in plants often exert significant influences on photosynthesis. As described in the introductory remarks, the effects are usually adverse. But virus infection does not always decrease all phases of 
photosynthetic activities $(1,14,20)$. The results obtained in this paper are further evidence on this point.

That there was no difference in Hill reaction rates between TEV-infected and healthy plants is supported by similar findings of Hopkins and Hampton (20). Their'rates of $\mathrm{FeCN}^{-3}$ reduction, however, were only about $70 \%$ of the rates reported here. Several explanations are possible, not the least of which is the environmental variation that can cause very large differences in Hill reaction rates of similar plants. They used the 3 top leaves, whereas the top leaves above a minimum length of $8 \mathrm{~cm}$ were used in this study; very young leaves do not support Hill activity as wel1 as more mature leaves (33). A1so, Hopkins and Hampton (20) used Tris-HCl, which is not as favorable an isolation buffer for chloroplast-mediated reduction of $\mathrm{FeCN}^{-3}$ as the Tricine-NaOH used here.

Hopkins and Hampton (20) found no difference in photophosphorylation rates between TEV-infected and healthy plants. But in a prior study (19) they had found that the $\mathrm{C}^{14} \mathrm{O}_{2}$ assimilation was reduced $40-50 \%$ per chloroplast in the virus infected tissue. This indicates that TEV infection affects the dark reactions of photosynthesis rather than the light reactions. 
Livne (25) found a marked stimulation of $\mathrm{C}^{14} \mathrm{O}_{2}$ uptake in noninfected trifoliolate leaves of bean plants where unifoliate leaves had been inoculated with either of two species of rust fungi. The higher the disease intensity in primary leaves, the more the increase in photosynthesis of the noninfected trifoliolate leaves :

No increase in rates of the Hill reaction occurred in uninoculated half-leaves of plants whose opposite hảifleaves had been inoculated with TNV. Ross (28) hảs shown that inoculation of half-leaves of tobacco with one 6 fe several local lesion-inducing viruses induces à high level of resistance to similar viruses in the opposite haletleaves. The same type of resistance also develops in leaves above and below those leaves which are inoculated with the virus. This resistance is operative by the third dày after inoculation. Bozarth and kòss (8) found that respiration rates in resistant tissue are not appreciably different from rates of control leaves: Polyphenoloxidase activity was also similar in resistant and control ieaves:

The difference in Hili reaction rates between tiRS infected plants and healthy controls is qualitativièy the same as the results obtained earlier (1). The recoviered tissue used in the earlier study came from plants inoculated 
7 weeks prior to assay, and rates in it were expressed in terms of change in $O D$.

Roberts and corbett (27), using manometry; found thak $\mathrm{O}_{2}$ evolution from leá discs was reduced $23-24 \%$ in recoverèd leaves of TRSV-infected tobacco plants: This finding $\dot{i}$ is in apparent contradiction with the significantly elevated Hili reaction rates in infected plants obtained here; as there should be a stoichiometric equality between the $\mathrm{O}_{2}$ eviolived and the amount of oxidant reduced: How; then does one reecon= cile the difference between these findings? One possibilitey is that the isolation of chioroplasts from virus-infected plants enhances photosystem II, such that $\mathrm{FeCN}^{-3}$ is reduced at higher rates in these chioroplastis thàn in those frồm healthy plants (Fig: 4):

Another possibility is that the $\mathrm{o}_{2}$ produced in photô $=$ system II may be used to reoxidize the reduced ferredoxin of photosystem I when there is no oxidized NADP present (4): It may be that in diseased tissue there is a siower turn= over of NADP than in healthy tissue and that $\mathrm{O}_{2}$ is used for reoxidation of the ferredoxin. This would not affect the rate of $\mathrm{FeCN}^{-3}$ reduction: This could explain reduced $\mathrm{o}_{2}$ evolution in leaf discs and increased rätes of $\mathrm{FeCN}^{-3}$ ree $=$ duction in chloropiasts of the virus-infected tissue 


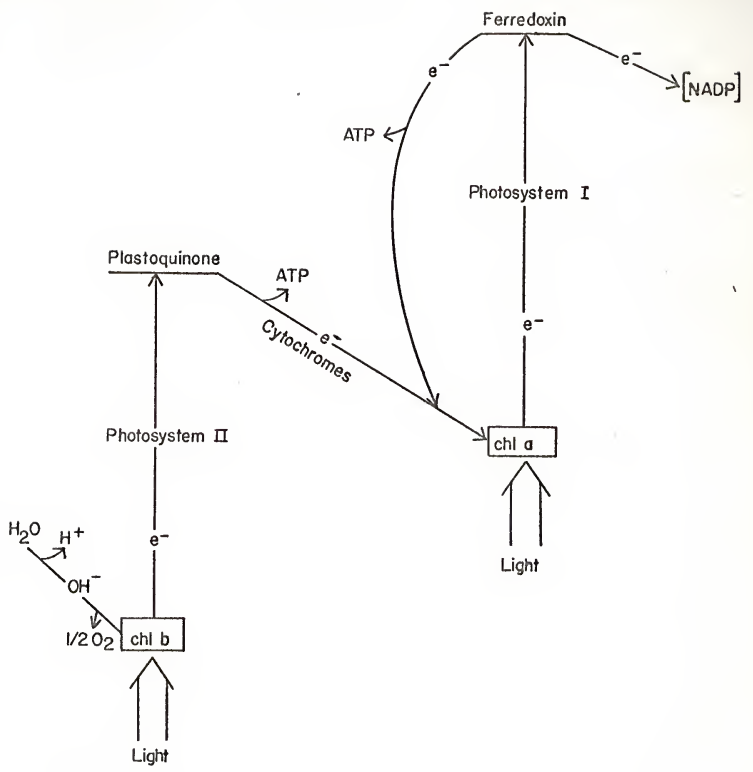

Figure 4. Electron transport path of photoreactions in isolated chloroplasts (6). 
Still a third possibility is a preferential uncoupling of the Hill reaction from photophosphorylation in chloroplasts from TRSV-infected plants. Good (15) has shown that many substances (ammonia, organic amines, most anions) stimulate Hill reaction rates as much as 20 -fold, because they uncouple phosphorylation from electron transport. It is certainly possible that some chemical by-product of the virus infection could act equally well as an uncoupler, resulting in higher rates of $\mathrm{FeCN}^{-3}$ reduction. This possibility can be tested by a study of the photophosphorylation rates in TRSV-infected and healthy tobacco; it is also a simple, and perhaps the best, explanation for the difference between the results in this paper and those of Roberts and Corbett (27).

Studies of the Hill reaction as affected by virus infection have not yet answered many general questions as to what is happening in the infection process. The obvious and relatively simple procedure to use in studying photosynthesis as affected by viruses is a measurement of $\mathrm{CO}_{2}$ uptake, done most easily with infra-red gas analysis. From a practical standpoint, it is this parameter of photosynthesis that needs to be investigated and that also appears to be the segment of the process most readily affected. Once having determined a difference between healthy and infected 
plants, one could then more efficiently study the more complicated aspects of the photosynthetic process. 


\section{SUMMARY}

Hill reaction rates in isolated chloroplasts were more reliably determined if a concentration of less than $30 \mu \mathrm{g}$ chlorophyll/3 $\mathrm{ml}$ was used for measuring the reduction of $\mathrm{FeCN}^{-3}$ spectrophotometrically. Using a differential centrifugation for chloroplasts isolated in Tris-HCl or Tricine- $\mathrm{NaOH}, 20 \mu \mathrm{g} / 3 \mathrm{ml}$ was optimal; for chloroplasts isolated by a single centrifugation in MES- $\mathrm{NaOH}$ or pyrophosphate-HCl, $10 \mu \mathrm{g} / 3 \mathrm{ml}$ was best.

Tricine-NaOH was better than Tris-HCl for isolation of spinach and tobacco chloroplasts. Tris-HCl, in turn, was a better buffer than MES-NaOH or pyrophosphate-HCl for j.solation of spinach chloroplasts.

Tobacco chloroplasts supported higher Hill reaction rates than market-spinach chloroplasts when both were isolated in Tricine-NaOH. Tris-HCl sustained slightly higher rates than Tricine- $\mathrm{NaOH}$ when used as the assay buffer.

Confirmation was obtained for the fact that there is no difference in Hill reaction rates between plants infected with TEV and healthy plants. 
Inoculation of half-leaves of tobacco with TNV induced no apparent change in Hill reaction rates of chloroplasts isolated from the opposite half-leaves 3 days after inoculation.

Chloroplasts from recovered leaves of TRSV-infected plants reduced $\mathrm{FeCN}^{-3}$ at higher rates than chloroplasts from healthy plants. This finding, in apparent contradiction with the finding of decreased $\mathrm{O}_{2}$ evolution of TRSV-infected leaf discs (27), may be most probably explained by a greater uncoupling of Hill reaction rates in chloroplasts from TRSVinfected plants than in those from healthy plants. 


\section{IITERATURE CITED}

1. Archer, M. C. 1969. Increased photosynthetic activity in chloroplasts from leaves chronically infected with tobacco ringspot virus. Phytopathology 59:111. (Abstr.)

2. Arnon, D. I. 1949. Copper enzymes in isolated chloroplasts. Polyphenoloxidase in Beta vulgaris. Plant Physiol. 24:1-15.

3. Arnon, D. I., M. B. Allen, and F. R. Whatley. 1954. Photosynthesis by isolated chloroplasts. Nature 174: 394-396.

4. Arnon, D. I., H. Y. Tsujimoto, and B. D. McSwain. 1967. Ferredoxin and photosynthetic phosphorylation. Nature 214:562-566.

5. Avron, M., D. W. Krogmann, and A. T. Jagendorf. 1958. The relation of photosynthetic phosphorylation to the Hill reaction. Biochim. Biophys. Acta 30:144-153.

6. Avron, M., and J. Neumann. 1968. Photophosphorylation in chloroplasts. Ann. Rev. Plant Physiol. 19:137166 .

7. Avron, M. and N. Shavit. 1963. A sensitive and simple method for determination of ferrocyanide. Anal. Biochem. 6: 549-554.

8. Bozarth, F. R., and A. F. Ross. 1964. Systemic resistance induced by localized virus infections: extent of changes in uninfected plant parts. Virology 24: $446-455$.

9. Büchner, E. 1897. Alkoholische Garung ohne Hefezellen (2nd Report). Ber. Deut. Chem. Ges. 30:110. 
10. Bucke, C., D. A. Walker, and C. W. Baldry. 1966. Some effects of sugars and sugar phosphates on carbon dioxide fixation by isolated chloroplasts. Biochem. J. 101:636-641.

11. Cockburn, W., D. A. Walker, and C. W. Baldry. 1968. Photosynthesis by isolated chloroplasts. Biochem. J. 107:89-95.

12. Cockburn, W., D. A. Walker, and C. W. Baldry. 1968. The isolation of spinach chloroplasts in pyrophosphate media. Plant Physiol. 43:1415-1418.

13. Diener, T. O. 1963. Physiology of virus-infected plants. Ann. Rev. Phytopathol. 1:197-218.

14. Goffeau, A., and J. M. Bové: 1965. Virus infection and photosynthesis. I. Increased photophosphorylation by chloroplasts from Chinese cabbage infected with turnip yellow mosaic virus. Virology 27:243-252.

15. Good, N. E. 1962. Uncoupling of the Hill reaction from photophosphorylation by anions. Arch. Biochem. Biophys. 96:653-661.

16. Good, N. E., G. D. Winget, W. Winter, T. N. Connolly, S. Izawa, and R. M. M. Singh. 1966. Hydrogen ion buffers for biological research. Biochem. 5:467-477.

17. Hampton, R. E., D. L. Hopkins, and T. G. Nye. 1966. Biochemical effects of tobacco etch virus infection on tobacco leaf tissue. I. Protein synthesis by isolated chloroplasts. Phytochemistry 5:1181-1185.

18. Hill, R. 1939. Oxygen produced by isolated chloroplasts. Proc. Roy. Soc., B. 127:192-210.

19. Hopkins, D. I., and R. E. Hampton. 1967. Effects of tobacco etch virus on photosynthesis. Phytopathology $57: 815$. (Abstr.)

20. Hopkins, D. I., and R. E. Hampton. 1969. Effects of tobacco etch virus infection upon the light reactions of photosynthesis in tobacco leaf tissue. Phytopathology 59:677-679. 
21. Jensen, R. G., and J. A. Bassham. 1966. Photosynthesis by isolated chloroplasts. Proc. Nat. Acad. Sci. $56: 1095-1101$.

22. Kalberer, P. P., B. B. Buchanan, and D. I. Arnon. 1967. Rates of photosynthesis by isolated chloroplasts. Proc. Nat. Acad. Sci. 57:1542-1549.

23. Krogmann, D. W., and Jagendorf, A. T. 1957. A, spectrophotometric assay of the Hill reaction with ferricyanide. Plant Physiol. 32:373.

24. Leech, R. M. 1964. The isolation of structurally intact chloroplasts. Biochim. Biophys. Acta 79:637639.

25. Livne, A. 1964. Photosynthesis in healthy and rustaffected plants. Plant Physiol. 39:614-621.

26. Owen, P. C. 1957. The effects of infection with tobacco mosaic virus on the photosynthesis of tobacco leaves. Ann. App1. Biol. 45:456-461.

27. Roberts, D. A., and M. K. Corbett. 1965. Reduced photosynthesis in tobacco plants infected with tobacco ringspot virus. Phytopathology 55:370-371.

28. Ross, A. F. 1961. Systemic acquired resistance induced by localized virus infections in plants. Virology 14:340-358.

29. Spikes, J. D., and M. Stout. 1955. Photochemical activity of chloroplasts isolated from sugar beet infected with virus yellows. Science 122:375-376.

30. Walker, D. A. 1964. Improved rates of carbon dioxide fixation by illuminated chloroplasts. Biochem. J. $92: 22 c-23 c$.

31. Walker, D. A. 1965. Correlation between photosynthetic activity and membrane integrity in isolated pea chloroplasts. Plant Physiol. 40:1157-1161.

32. Warburg, O. 1949. Heavy metals and prosthetic groups. clarendon Press. London. p. 214. 
33. Zaitlin, M., and A. T. Jagendorf. 1960. Photosynthetic phosphorylation and Hill reaction activities of chloroplasts isolated from plants infected with tobacco mosaic virus. Virology 12:477-486. 


\section{BIOGRAPHICAL SKETCH}

Milton C. Archer, Jr. was born December 7, 1940, in Jacksonville, Florida. He attended public school there, graduating from Julia Landon High School in June, 1958. He received a Bachelor of Science in Agriculture degree with a major in Agronomy from the University of Florida in December, 1962.

Mr. Archer taught in the secondary school system in Jacksonville for 6 months and then served 6 months on active duty in the U. S. Army. He then worked for the General Electric Company until January, 1965, at which time he entered graduate school in the department of plant pathology. His degree of Doctor of Philosophy is to be granted in August, 1969. 
This dissertation was prepared under the direction of the chairman of the candidate's supervisory committee and has been approved by all the members of that committee. It was submitted to the Dean of the College of Agriculture and to the Graduate Council, and was approved as partial fulfillment of the requirements for the degree of Doctor of Philosophy .

August, 1969

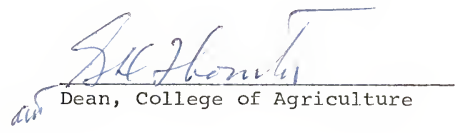

Dean, Graduate School

Supervisory Committee:
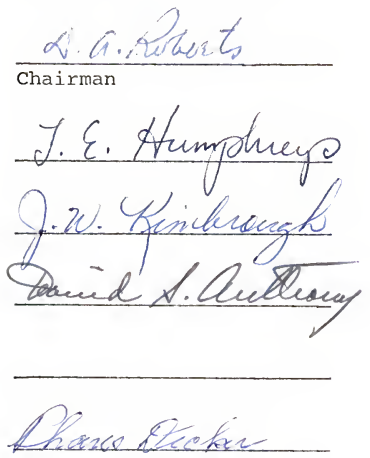